\title{
Combinational effect of genes for the renin-angiotensin system in conferring susceptibility to diabetic nephropathy
}

\author{
Norihisa Osawa $\cdot$ Daisuke Koya $\cdot$ Shin-ichi Araki $\cdot$ Takashi Uzu $\cdot$ \\ Tatsuhiko Tsunoda $\cdot$ Atsunori Kashiwagi $\cdot$ Yusuke Nakamura \\ Shiro Maeda
}

Received: 1 October 2006/ Accepted: 4 November 2006/Published online: 2 December 2006

(C) The Japan Society of Human Genetics and Springer 2006

\begin{abstract}
To elucidate the role of the renin-angiotensin system (RAS) in diabetic nephropathy, we examined the association between diabetic nephropathy in a large cohort of Japanese type 2 diabetic patients and polymorphisms within the genes that encode angiotensin-converting enzyme $(A C E)$, angiotensinogen $(A G T)$ and angiotensin II receptor type 1 (AGTR1). Single nucleotide polymorphisms (SNPs) within these genes were genotyped using invader assay in 747 nephropathy cases and 557 control subjects. Eight SNPs within the $A C E$ gene were significantly associated with diabetic nephropathy $(P<0.05)$,
\end{abstract}

Electronic supplementary material Supplementary material is available in the online version of this article at http://dx.doi.org/ $10.1007 / \mathrm{s} 10038-006-0090-5$ and is accessible for authorized users.

N. Osawa $\cdot$ D. Koya $\cdot$ S. Araki $\cdot$ T. Uzu .

A. Kashiwagi

Department of Medicine,

Shiga University of Medical Science,

Otsu, Shiga 520-2192, Japan

N. Osawa $\cdot$ S. Maeda $(\bowtie)$

Laboratory for Diabetic Nephropathy,

SNP Research Center, The Institute of Physical

and Chemical Research, 1-7-22 Suehiro-cho,

Tsurumi-ku, Yokohama, Kanagawa 230-0045, Japan

e-mail:smaeda@src.riken.jp

T. Tsunoda

Laboratory for Medical Informatics, SNP Research Center,

The Institute of Physical and Chemical Research,

Yokohama, Kanagawa 230-0045, Japan

\section{Y. Nakamura}

Laboratory of Molecular Medicine,

Human Genome Center, The Institute of Medical Science,

University of Tokyo, Tokyo 108-8639, Japan including five SNPs in almost complete linkage disequilibrium to the insertion/deletion polymorphism in the 16th intron $(P=0.01$, odds ratio $=1.34,95 \%$ CI 1.07 1.69). Three SNPs within the $A G T$, including M235T and one SNP in the AGTR1, were also significantly associated with nephropathy (M235T $P=0.01$, odds ratio $=0.74,95 \%$ CI $0.59-0.94$ ). In addition, we found that the allelic mRNA expression corresponding to the $235 \mathrm{M}$ allele was significantly higher than that for the $235 \mathrm{~T}$ allele in normal kidney tissues. Furthermore, we found a significant additional effect of these three genes by a step-wise logistic regression analysis (final empirical $P$ value $=0.00005$ ). We concluded that RAS gene polymorphisms may contribute to the susceptibility to diabetic nephropathy in type 2 diabetes.

Keywords Diabetic nephropathy · Polymorphism . $A C E \cdot A G T \cdot A G T R 1 \cdot$ Type 2 diabetes

\section{Introduction}

Diabetic nephropathy is the leading cause of end-stage renal disease in Western countries and Japan [excerpts from the United States Renal Data System (USRDS) 2001; Patient Registration Committee 2002]. Several genetic and environmental factors are likely to contribute to its development and progression, although the precise mechanisms for these contributions are unknown. Some studies have indicated that the systemic and/or intrarenal renin-angiotensin system plays a pivotal role in the pathogenesis of diabetic nephropathy (Cooper et al. 2001; Leehey et al. 2000). Local production of angiotensin II is considered to mediate the increase of intraglomerular pressure via 
constriction of efferent arterioles and thus contributes to the development and progression of glomerulosclerosis seen in various renal diseases, including diabetic nephropathy. It has also been shown that angiotensin II is able to stimulate the production of several cytokines, such as TGF- $\beta$ (Kagami et al. 1994) or reactive oxygen species (Jaimes et al. 1998) and to mediate the over-accumulation of extracellular matrix proteins or cause various cellular dysfunctions under diabetic conditions. In addition, some clinical trials have demonstrated that blockage of angiotensin II with either ACE inhibitor or an angiotensin type-I receptor antagonist was able to prevent or delay the progression of renal injury associated with diabetes (Lewis et al. 1993; Brenner et al. 2001), and now these drugs have been recommended as first-choice drugs for the treatment of diabetic subjects with hypertension (American Diabetes Association 2004). Therefore, the importance of the renin-angiotensin system with respect to the pathogenesis of diabetic nephropathy is well established. However, the precise mechanism for the regulation of the renin-angiotensin system in subjects with diabetes mellitus remains unknown.

In contrast, accumulating evidence suggests that genetic susceptibility plays an important role in the development and progression of diabetic nephropathy. The genes encoding some components of the reninangiotensin system (RAS), such as angiotensin-converting enzyme [ACE (MIM 106180)], angiotensinogen [AGT (MIM 106150)] and angiotensin II receptor type 1 [AGTR1 (MIM 106165)], have been reported to be the most probable candidate genes for diabetic nephropathy. An insertion/deletion (I/D) polymorphism in the 16th intron of the $A C E$ gene was reported to be associated with blood pressure and plasma levels of ACE (Rigat et al. 1990). The I/D polymorphism has also been reported to be associated with renal expression of ACE (Mizuiri et al. 2001) as well as susceptibility to diabetic nephropathy. The association of CSNP with substitution of methionine at codon 235 to threonine (M235T) in $A G T$ and a SNP in the $3^{\prime} \mathrm{UTR}$ of AGTR1 (A1166C) with diabetic nephropathy has also been examined. In addition, several reports have demonstrated an interaction among these RAS gene polymorphisms. One study indicated that the $A C E \mathrm{I} / \mathrm{D}$ and $A G T$ M235T polymorphisms interacted significantly in subjects with type 1 diabetes (Marre et al. 1997). It was also reported that the number of $\mathrm{D}$ ( $A C E$ I/D)/M ( $A G T$ M235T)/A (AGTR1 A1166C) alleles influenced the rate of the deterioration of renal function (Jacobsen et al. 2003). However, to date, the results for the association of these RAS genes with diabetic nephropathy have been inconclusive.
In the present study, we investigated the association between these RAS gene polymorphisms and the development and progression of diabetic nephropathy in type 2 diabetes and provide evidence that shows that the $A C E, A G T$ and $A G T R 1$ genes may be independently involved in the susceptibility to diabetic nephropathy.

\section{Materials and methods}

\section{DNA preparation and genotyping}

DNA samples were obtained from the peripheral blood of patients with type 2 diabetes who regularly attend outpatient clinics at Shiga University of Medical Science, Tokyo Women's Medical University, Juntendo University, Kawasaki Medical School, Iwate Medical University, Toride Kyodo Hospital, Kawai Clinic, Osaka City General Hospital, or Chiba Tokusyukai Hospital. All subjects provided informed consent and were enrolled in this study between 1996 and 2003. DNA extraction was performed according to a standard phenol-chloroform protocol. Diabetic patients were divided into two groups according to the following diagnostic criteria: (1) cases of diabetic nephropathy, i.e., patients with diabetic retinopathy as well as overt nephropathy, indicated by urinary albumin excretion rates (AERs) $\geq 200 \mu \mathrm{g} / \mathrm{min}$ or urinary albumin-to-creatinine ratios $(\mathrm{Alb} / \mathrm{Cr}) \geq 300 \mathrm{mg} / \mathrm{g} \mathrm{Cr}$ or patients under chronic renal-replacement therapy; (2) control patients with diabetic retinopathy, but showing normal urinary albumin excretion, i.e., AER $<20 \mu \mathrm{g} /$ $\mathrm{min}$ or $\mathrm{Alb} / \mathrm{Cr}<30 \mathrm{mg} / \mathrm{g} \mathrm{Cr}$. Clinical characteristics of the subjects are shown in Table 1. There are significant differences in gender distribution, duration of diabetes and blood pressures between the case and control groups. SNPs within the $A C E, A G T$ and $A G T R 1$ genes were selected from the IMS-JST SNP database

Table 1 Clinical characteristics of the patients

\begin{tabular}{llll}
\hline & Case & Control & $P$ \\
\hline$n$ & 747 & 557 & \\
Sex (M:F) & $504: 243$ & $270: 287$ & $<0.0001^{\mathrm{a}}$ \\
Age & $60.1 \pm 11.7$ & $62.4 \pm 10.4$ & 0.0004 \\
Duration (year) & $19.3 \pm 9.7$ & $15.3 \pm 8.9$ & $<0.0001$ \\
HbA1c (\%) & $7.6 \pm 3.6$ & $7.6 \pm 1.2$ & 0.98 \\
BMI (kg/m $\left.{ }^{2}\right)$ & $23.8 \pm 3.7$ & $23.6 \pm 3.3$ & 0.41 \\
SBP $(\mathrm{mmHg})$ & $148 \pm 20$ & $136 \pm 17.0$ & $<0.0001$ \\
DBP $(\mathrm{mmHg})$ & $80 \pm 11$ & $77 \pm 10$ & $<0.0001$ \\
\hline
\end{tabular}

Data are shown as means $\pm \mathrm{SD}$; statistical significance between the two groups was analyzed using the unpaired Student's $t$ test

${ }^{a}$ Chi square test 
(available at http://www.snp.ims.u-tokyo.ac.jp) and analyzed in 747 cases and 557 controls by Invader assay, as previously described (Ohnishi et al. 2001). We also determined the genotype of I/D polymorphisms within the $A C E$ gene in 94 control subjects to calculate the linkage disequilibrium coefficient $(\Delta)$ between the $A C E$ SNPs and the I/D polymorphisms using a PCR method as described previously (Cambien et al. 1992). The protocol was approved by the Ethics Committee of the Institute of Physical and Chemical Research.

\section{Statistical analysis}

We assessed the difference in the genotype and/or allele frequencies between case and control groups by chi-square test. To analyze clinical data, the statistical significance between any two groups was analyzed by one-way analysis of variance followed by Sheffe's test. We calculated odds ratios and $95 \%$ confidence intervals (CI) with respect to the minor allele compared with the major allele. We calculated LD coefficients $(\Delta)$ as described previously (Yamada et al. 2001). We also analyzed the interaction among the SNPs within the RAS genes by step-wise logistic regression analysis according to a previously described method (Cordell and Clayton 2002; Kanazawa et al. 2004). Briefly, the probability, $P$, of an individual being a case rather than a control is assumed to be affected by a set of SNPs according to the logistic model: for example, $\operatorname{logit}(P)=a_{0}+a_{1} x_{1}+a_{2} x_{2}$ for single SNP. Here, we use a coding scheme $x_{1}=-1,0$, 1 and $x_{2}=-0.5,0.5,-0.5$ for genotypes $1 / 1,1 / 2$ and $2 / 2$, respectively, to represent an additive effect by $x_{1}$ and a dominance/recessive effect by $x_{2}$ (Cordell and Clayton 2002). The weights are estimated by the maximumlikelihood method and tested by comparison with the null-hypothesis $\operatorname{logit}(P)=a_{0}$ (constant). For multiple SNPs, interaction effects are added further in addition to the main effects of additional SNPs and tested stepwise whether their effects were significant or not. The tests were performed using $R$.

Measurement of M235T allelic mRNA expression for the $A G T$

One microgram of total RNA prepared from the kidney tissues with informed consent was reverse-transcribed using the SuperScript first-strand synthesis system (Invitrogen), and the cDNA was subjected to PCR reaction with the following primers to amplify target fragments: forward: 5'-GAGAAGATTGACA GGTTCATGCAG-3'; reverse: 5'-GTCACCGAGAA GTTGTCCTGG-3'. For the determination of allelic mRNA expression, the invader assay was performed, and a real-time intensity of fluorescence (FAM for $235 \mathrm{M}$, and Yellow for 235T) was measured using the $\mathrm{M} \times 3000 \mathrm{P}$ Multiplex Quantitative PCR system (STRATAGENE, La Jolla, CA). Sequential dilution of an amplified product from genomic DNA of the subjects with heterozygousity for the $A G T$ gene M235T polymorphism was used for making standard curbs for each allele. The allelic mRNA expression for each allele was compared individually for five subjects, and the statistical difference was analyzed by paired $t$-test. In addition, the ratio of mRNA corresponding to $235 \mathrm{M}$ to $235 \mathrm{~T}$ was compared to that of internal controls; those were amplified products from genomic DNAs for four subjects with heterozygousity of the M235T polymorphism, and the difference was evaluated with an unpaired $t$-test.

\section{Results}

Association of SNPs in the RAS genes with diabetic nephropathy

Ten SNPs within the $A C E$ gene were successfully genotyped (Fig. 1; Supplementary Table 1; nine intronic SNPs and one synonymous SNP in the 16th exon). As shown in Fig. 1, eight SNPs were significantly associated with diabetic nephropathy $(P<0.05)$, and among them, five SNPs were almost in complete linkage disequilibrium with the I/D polymorphism within the 16 th intron of the gene $(\Delta=1$, Fig. 1$)$. We found a significant association between several SNPs within the $A C E$ gene and diabetic nephropathy, and the allele corresponding to the $\mathrm{D}$ allele for the $\mathrm{I} / \mathrm{D}$ polymorphism was identified as a risk factor for diabetic nephropathy $(P=0.01$, odds ratio $=1.34$, 95\% CI 1.07-1.69, Fig. 1; Table 2, Supplementary Table 1). Interestingly, this association was mainly observed in the female group (Table 2).

Regarding the $A G T$ gene, six SNPs including the M235T polymorphism were identified (Fig. 2; Supplementary Table 2), and M235T and two other SNPs were significantly associated with diabetic nephropathy (M235T: $P=0.01$, odds ratio $=0.74,95 \%$ CI $0.59-0.94$, Fig. 2; Table 2, Supplementary Table 2). We also found a gender-specific association of the M235T polymorphism with diabetic nephropathy in the female group (Table 2).

In the AGTR1 gene, 26 SNPs were genotyped (Fig. 3; Supplementary Table 3), and 23 SNPs were located in introns. Three SNPs including the A1166C polymorphism were located in exons. None of the mutations were predicted to cause amino acid 
Fig. 1 Analysis of polymorphisms within the $A C E$ gene. a The structure of the $A C E$ gene and localization of 16th intron insertion/deletion polymorphism (asterisk) and ten SNPs selected from the IMS-JST SNP database. b Linkage disequilibrium coefficient $(\Delta)$ between each SNP and the I/D

polymorphism. c Result of chi-square test. Bars over the horizontal breaking line (\#) were considered to be significant $(P<0.05)$ a
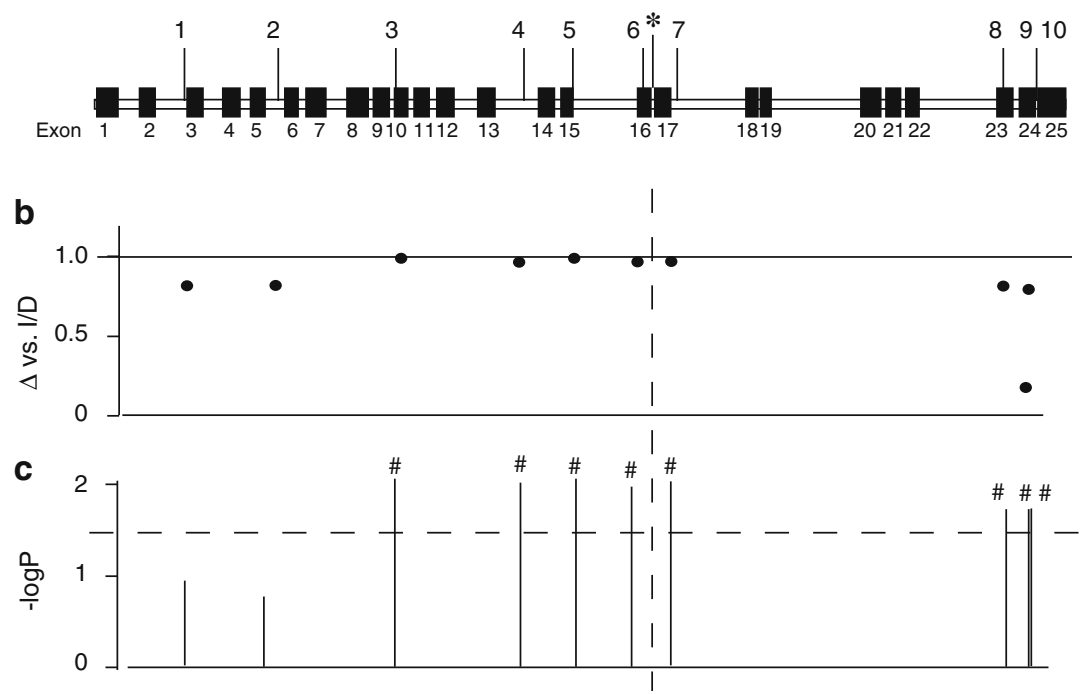

Table 2 Association of the RAS polymorphism with diabetic nephropathy

\begin{tabular}{|c|c|c|c|c|}
\hline & Genotype & Allele & Dominant & Recessive \\
\hline \multicolumn{5}{|c|}{ [rs4344: $A C E \Delta=1$ vs. I/D intron $17+231(\mathrm{G}>\mathrm{A})$ ] } \\
\hline \multicolumn{5}{|c|}{ Total } \\
\hline$P$ & 0.03 & 0.049 & 0.011 & 0.81 \\
\hline OR $(95 \% \mathrm{Cl})$ & & $1.18(1.00-1.40)$ & $1.34(1.07-1.69)$ & $1.04(0.74-1.46)$ \\
\hline \multicolumn{5}{|l|}{ Male } \\
\hline$P$ & 0.29 & 0.44 & 0.19 & 0.69 \\
\hline OR $(95 \% \mathrm{Cl})$ & & $1.09(0.87-1.37)$ & $1.22(0.90-1.66)$ & $0.91(0.59-1.43)$ \\
\hline \multicolumn{5}{|l|}{ Female } \\
\hline$P$ & 0.01 & 0.01 & 0.004 & 0.44 \\
\hline OR $(95 \% \mathrm{Cl})$ & & $1.38(1.06-1.79)$ & $1.69(1.18-2.44)$ & $1.24(0.72-2.12)$ \\
\hline \multicolumn{5}{|c|}{$[$ rs699 (M235T), $A G T$ exon $2+806(\mathrm{~T}>\mathrm{C})]$} \\
\hline \multicolumn{5}{|c|}{ Total } \\
\hline$P$ & 0.029 & 0.039 & 0.012 & 0.77 \\
\hline OR $(95 \% \mathrm{Cl})$ & & $0.81(0.66-0.99)$ & $0.74(0.59-0.94)$ & $1.10(0.57-2.15)$ \\
\hline \multicolumn{5}{|l|}{ Male } \\
\hline$P$ & 0.59 & 0.34 & 0.83 & 0.31 \\
\hline OR $(95 \% \mathrm{Cl})$ & & $0.88(0.67-1.15)$ & $0.85(0.62-1.16)$ & $0.92(0.41-2.03)$ \\
\hline \multicolumn{5}{|l|}{ Female } \\
\hline$P$ & 0.03 & 0.03 & 0.012 & 0.77 \\
\hline OR $(95 \% \mathrm{Cl})$ & & $0.71(0.52-0.98)$ & $0.63(0.43-0.90)$ & $1.20(0.34-4.20)$ \\
\hline \multicolumn{5}{|c|}{ [rs388915: AGTR1 intron $2+21,942(\mathrm{~T}>\mathrm{C})]$} \\
\hline \multicolumn{5}{|l|}{ Total } \\
\hline$P$ & 0.029 & 0.59 & 0.19 & 0.06 \\
\hline OR $(95 \% \mathrm{Cl})$ & & $0.94(0.76-1.17)$ & $0.85(0.67-1.08)$ & $1.93(0.95-3.92)$ \\
\hline \multicolumn{5}{|l|}{ Male } \\
\hline$P$ & 0.22 & 0.92 & 0.53 & 0.17 \\
\hline OR $(95 \% \mathrm{Cl})$ & & $0.99(0.74-1.31)$ & $0.90(0.65-1.25)$ & $1.99(0.73-5.42)$ \\
\hline \multicolumn{5}{|l|}{ Female } \\
\hline$P$ & 0.06 & 0.42 & 0.15 & 0.17 \\
\hline OR $(95 \% \mathrm{Cl})$ & & $0.87(0.62-1.22)$ & $0.75(0.51-1.11)$ & $2.02(0.72-5.64)$ \\
\hline
\end{tabular}

substitutions. One SNP within the second intron was significantly associated with diabetic nephropathy $(P=0.029$, Fig. 3; Table 2). In our study, however, the A1166C polymorphism was not associated with diabetic nephropathy $(P=0.17$, Fig. 3$)$.
We further evaluated interactions among the SNPs within the RAS genes by step-wise logistic regression analysis. The analysis was based on a full genotype model that includes all effects of additive, dominance/ recessive and interaction between SNPs (see Materials 
Fig. 2 Analysis of SNPs within the $A G T$ gene. a The structure of the $A G T$ gene and localization of each SNP. An asterisk indicates the M235T polymorphism. b Linkage disequilibrium coefficient $(\Delta)$ between each SNP and the M235T polymorphism. c Result of chi-square test for the association study



a
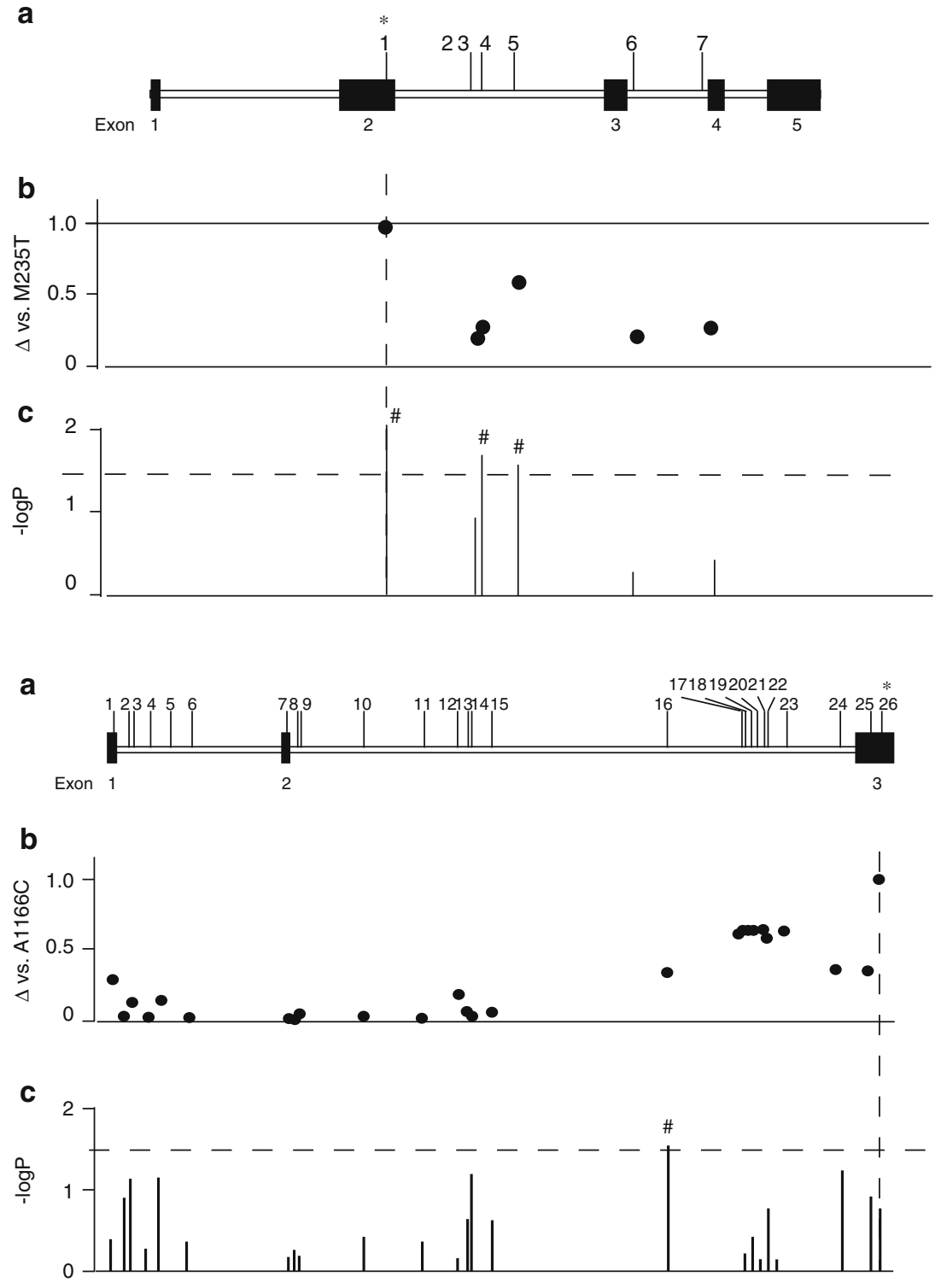

Fig. 3 Analysis of SNPs within the $A G T R 1$ gene. a The structure of the AGTR1 gene and localization of each SNP. An asterisk indicates the A1166C polymorphism. b Linkage disequilibrium coefficient $(\Delta)$ between each SNP and A1166C polymorphism. c Result of chi-square test for the association study and methods). The result indicated that there was no significant synergistic interaction among any of the SNPs examined. However, the significant additional effect of several SNPs (SNP at intron $17+231$ and intron $24+97$ of the $A C E$ gene, M235T SNP of the $A G T$ gene and SNP at intron $2+21,942$ of the $A G T R 1$ gene) was detected in this population (final empirical $P$ value $=0.00005$, Table 3 ).

The allelic mRNA expression of the $A G T$ corresponding to each allele for the M235T polymorphism

We measured the allelic mRNA expression for each allele using invader assay (see Materials and methods).
As a result, we could find that the mRNA expression corresponding to the $235 \mathrm{M}$ allele was higher than the mRNA corresponding to the $235 \mathrm{~T}$ allele in normal kidney tissues from all five individuals (Fig. 4). Also, the expression ratio for $235 \mathrm{M}$ to $235 \mathrm{~T}$ in the kidney was shown to be significantly increased compared to that for the genomic DNA from heterozygous subjects, which was considered to be an internal control $(3.20 \pm 1.41,0.98 \pm 0.11$, kidney mRNA, and genomic DNA, respectively, $P=0.017$ ).

\section{Discussion}

In this study we found a significant association of the $A C E$ gene with diabetic nephropathy in a large cohort 
Table 3 Results of step-wise logistic regression analysis

\begin{tabular}{|c|c|c|c|c|c|}
\hline \multicolumn{2}{|c|}{ Combination of SNPs } & \multicolumn{2}{|l|}{ Significance of addition } & \multicolumn{2}{|c|}{ Combined empirical $P$ value } \\
\hline \multirow{4}{*}{\multicolumn{2}{|c|}{$\begin{array}{l}\text { rs388915 } \\
\text { rs388915 + rs2242638 } \\
\text { rs388915 + rs2242638 + rs699 } \\
\text { rs388915 + rs2242638 + rs699+rs4344 }\end{array}$}} & \multicolumn{2}{|l|}{-} & \multicolumn{2}{|c|}{-} \\
\hline & & \multicolumn{2}{|l|}{0.01} & \multicolumn{2}{|c|}{0.00075} \\
\hline & & \multicolumn{2}{|l|}{0.02} & \multicolumn{2}{|c|}{0.00017} \\
\hline & & \multicolumn{2}{|l|}{0.03} & \multicolumn{2}{|c|}{0.00005} \\
\hline \multicolumn{6}{|c|}{ Number of risk genotype ${ }^{a}$} \\
\hline & 0 & 1 & 2 & 3 & 4 \\
\hline Case $(n=704)$ & $5(0.7 \%)$ & $103(14.6 \%)$ & $319(45.3 \%)$ & $264(37.5 \%)$ & $13(1.8 \%)$ \\
\hline Control $(n=508)$ & $13(2.6 \%)$ & $114(22.4 \%)$ & $217(42.7 \%)$ & $162(31.3 \%)$ & $2(0.4 \%)$ \\
\hline OR & 0.27 & 0.59 & 1.11 & 1.28 & 4.76 \\
\hline $95 \% \mathrm{Cl}$ & $0.1-0.77$ & $0.44-0.80$ & $0.88-1.40$ & $1.01-1.63$ & $1.07-21.2$ \\
\hline
\end{tabular}

${ }^{a}$ Risk genotype: CC for rs388915 (AGTR1); TT, TC for rs2242638 (ACE), TT for rs699 (AGT); GA, AA for rs4344 (ACE)

Fig. 4 Allelic expression of the AGT mRNA

corresponding to M235T polymorphism in the kidney. The allelic mRNA expression for each allele in the kidney tissue (left). Quantification of the control products amplified from genomic DNAs of heterozygous subjects (right). $* P<0.05$
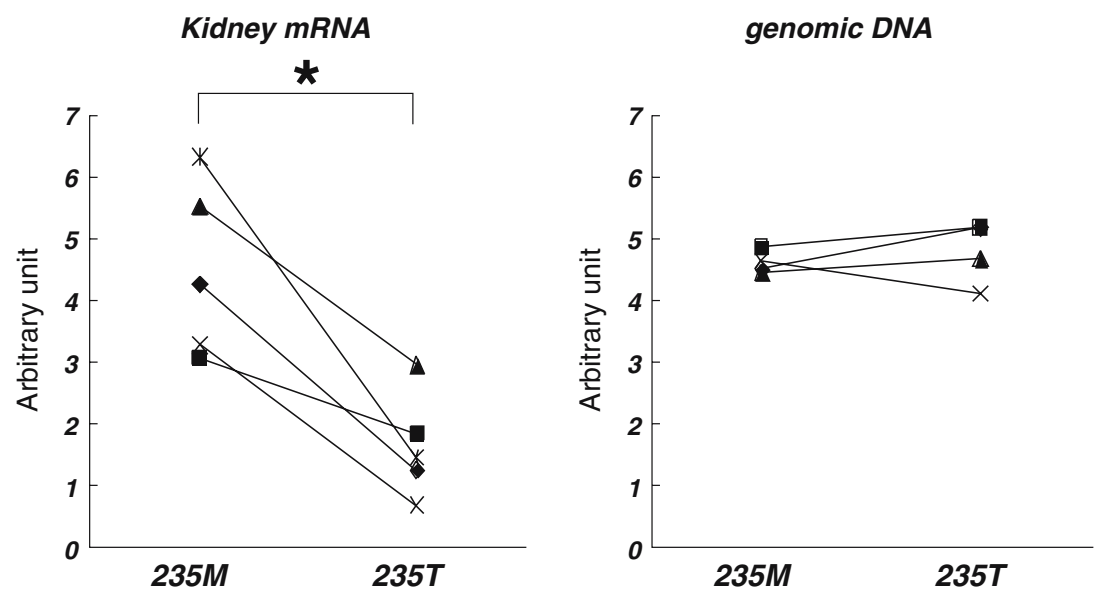

of Japanese subjects with type 2 diabetes. Our present results also suggest that the $A G T$ gene and the $A G T R 1$ gene also contribute to susceptibility to diabetic nephropathy, and these three genes may have a significant additional effect in conferring susceptibility to the disease.

The existence of genetic factors for the development and progression of diabetic nephropathy is well accepted, and the gene-encoding components of RAS are considered to be one of the most probable candidates. Furthermore, the association of RAS genes with diabetic nephropathy has been extensively examined, especially with respect to an insertion deletion polymorphism within the 16th intron of the $A C E$ gene. Although many reports have provided evidence that the $\mathrm{D}$ allele of the $A C E \mathrm{I} / \mathrm{D}$ polymorphism is a risk allele for the development and progression of diabetic nephropathy ( $\mathrm{Ng}$ et al. 2005; Tomino et al. 1999), several conflicting results have also been reported (Grzeszczak et al. 1998; Kimura et al. 1998). In the present study, we identified several SNPs that were almost in complete linkage disequilibrium with the I/D polymorphism, and these SNPs were significantly associated with diabetic nephropathy. The allele corresponding to the $\mathrm{D}$ allele for $\mathrm{I} / \mathrm{D}$ polymorphism was identified as a risk factor for diabetic nephropathy in our study population (Fig. 1; Table 2). Therefore, the results presented here are consistent with most previous reports.

The association of the $A G T$ and $A G T R 1$ genes with diabetic nephropathy has also been extensively examined, but, to date, the results have not been conclusive. The M235T polymorphism of the AGT gene was originally reported to be associated with hypertension (Jeunemaitre et al. 1992), and the TT genotype of this polymorphism was also shown to confer a risk for the progression of diabetic nephropathy (Freire et al. 1998). However, another study failed to identify the distinct role of the $A G T$ gene in conferring susceptibility to the disease (Zychma et al. 2000). From the results presented here, the carrier of the $M$ allele was thought to be at risk for nephropathy (Table 2).

The functional implications of this substitution are not fully understood. In this study, we examined the 
allelic $A G T$ gene expression corresponding to each allele for the M235T polymorphism in the kidney and found that the expression of the allelic mRNA corresponding to the $235 \mathrm{M}$ allele was consistently higher than mRNA corresponding to the 235T allele in the kidney tissues (Fig. 4). Since we examined the difference in the allelic mRNA expression in the individual kidney samples from heterozygous subjects, we could exclude the effects of environmental and/or other nongenetic factors, and then the present measurement of allelic mRNA expression was considered to directly reflect the genetic contribution itself. Therefore, the carrier of the $\mathrm{M}$ allele, rather than the $\mathrm{T}$ allele, may be more susceptible to diabetic nephropathy. In addition, Jacobsen et al. (2003) identified a combinational effect of the $\mathrm{D}$ allele of the $A C E$ gene and the $\mathrm{M}$ allele on the progression of diabetic nephropathy, further supporting our present finding. Regarding the AGTR1 gene, the A1166C polymorphism in the 3'UTR of the gene was reported to be associated with the progression of diabetic nephropathy in the Japanese population (Tomino et al. 1999), although most case-control studies did not identify a significant association of this polymorphism with diabetic nephropathy. The A1166C polymorphism was also not associated with the disease in the present population. Instead, we found a significant association between the SNP in the second intron of the AGTR1 gene and nephropathy. However, the association of this SNP with nephropathy was modest (Table 2), and further study will be required to evaluate a distinct effect of this polymorphism.

Because there were several differences in the clinical parameters between the case and control subjects (Table 1), we also analyzed the association of the RAS gene polymorphisms using control subjects with longer diabetes duration ( $\geq 10$ years), those whose diabetes duration was not different from the case group (case 19.3 \pm 9.7 , control 19.0 $\pm 7.5 ; P=0.58$ ), and identified the same association as the original finding (Supplementary Table 4). We also evaluated the effects of the
RAS gene polymorphisms in male and in female groups separately, since gender distribution was significantly different. Interestingly, some of the RAS gene polymorphisms contributed to the susceptibility to the disease in a gender-specific manner (Table 2). The gender-specific effects of the RAS genes have also been shown in previous reports (Tomino et al. 1999; Friere et al. 1998; Fradin et al. 2002), although the results were not always consistent, probably because of the differences in the ethnicity or in the number of the subjects evaluated.

Susceptibility to common diseases such as diabetic nephropathy is thought to be determined by several genetic factors. Therefore, the combinational effect of individual genes should be more emphasized. Regarding the RAS genes, several reports on type 1 diabetes suggested that there were some interactive effects among RAS gene polymorphisms in the development and progression of diabetic nephropathy (Marre et al. 1997; Jacobsen et al. 2003), although the results are not conclusive. To evaluate the interaction of the three genes examined in the present study more accurately, we applied a step-wise logistic regression analysis as previously reported (Cordell and Clayton 2002). Using this analysis, we were able to determine the significance of interactive and/or additional effects of all combinations, and therefore, we were able to evaluate the interactions of each gene more precisely. As a result, we found significant additional effects among SNPs at intron $17+231(\Delta=1$ vs. I/D), intron $24+97$ of the $A C E$ gene, M235T SNP of the $A G T$ gene and SNP at intron $2+21,942$ of the AGTR1 gene. Since we were unable to identify a synergistic effect of the genes, the effect of each of the three genes is likely to be independent, and simple additional effects could be observed. The results of logistic regression analysis also indicated that the increased number of risk alleles (alleles corresponding to the $\mathrm{D}$ allele, $\mathrm{C}$ allele for rs2242638 in the $A C E, \mathrm{M}$ allele for the $A G T$ and $\mathrm{C}$ allele of rs388915 for the AGTR1) was an independent

Table 4 Result of logistic regression analysis

\begin{tabular}{|c|c|c|c|c|c|}
\hline & $\beta$ & SE (b) & OR & $95 \% \mathrm{Cl}$ & $P$ \\
\hline Sex (male 1 ; female 2 ) & 0.821 & 0.177 & 2.27 & $1.61-3.22$ & $<0.0001$ \\
\hline Age & -0.040 & 0.008 & 0.96 & $0.95-0.98$ & $<0.0001$ \\
\hline BMI & 0.016 & 0.024 & 1.02 & $0.97-1.07$ & 0.51 \\
\hline Duration of diabetes & 0.060 & 0.010 & 1.06 & $1.04-1.08$ & $<0.0001$ \\
\hline HbA1c & 0.011 & 0.031 & 1.01 & $0.95-1.07$ & 0.73 \\
\hline Hypertension & 2.169 & 0.215 & 8.75 & $5.74-13.34$ & $<0.0001$ \\
\hline Number of risk genotype & 0.348 & 0.111 & 1.42 & $1.14-1.76$ & 0.0017 \\
\hline
\end{tabular}

$\beta$ Regression coefficient, $S E$ standard error, $O R$ odds ratio, $C l$ confidence interval 
risk for the development and progression of diabetic nephropathy $(P=0.0017$, OR $=1.42,95 \%$ CI: $1.14-1.76$; Table 4).

The mechanism by which the RAS gene polymorphisms contributes to the susceptibility to diabetic nephropathy should be elucidated. Although all SNPs within the RAS genes examined did not have any significant association with blood pressure or prevalence of hypertension in the present cross-sectional analysis (data not shown), further studies, such as a longitudinal prospective study or in vitro functional analysis, are necessary to elucidate the precise mechanism of the effect of the RAS gene in conferring susceptibility to diabetic nephropathy.

In conclusion, we identified significant associations between RAS gene polymorphisms and diabetic nephropathy in type 2 diabetes. Our present result from a step-wise logistic regression analysis also indicated that the ACE, AGT and AGTR1 genes may be independently involved in the susceptibility to diabetic nephropathy.

Acknowledgments We would like to thank Shuichi Tsukada, Masumi Kamiyama and the technical staff at the SNP Research Center and the Institute of Physical and Chemical Research.

\section{References}

American Diabetes Association (2004) Hypertension management in adults with diabetes. Diabetes Care 27(S1):S65-S67

Brenner BM, Cooper ME, de Zeeuw D, Keane WF, Mitch WE, Parving HH, Remuzzi G, Snapinn SM, Zhang Z, Shahinfar S (2001) RENAAL study investigators: effect of losartan on renal and cardiovascular outcomes in patients with type 2 diabetes and nephropathy. N Engl J Med 345:861-869

Cambien F, Poirier O, Lecerf L, Evans A, Cambou JP, Arveiler D, Luc G, Bard JM, Bara L, Ricard S, Tiret L, Amouyel P, Alhenc-Gelas F, Soubrier F (1992) Deletion polymorphism in the gene for angiotensin-converting enzyme is a potent risk factor for myocardial infarction. Nature 359:641-644

Cooper ME, Bonnet F, Oldfield M, Jandeleit-Dahm K (2001) Mechanisms of diabetic vasculopathy: an overview. Am J Hypertens 14:475-486

Cordell HJ, Clayton DG (2002) A unified stepwise regression procedure for evaluating the relative effects of polymorphisms within a gene using case/control or family data: application to $H L A$ in type 1 diabetes. Am J Hum Genet 70:124-141

Excerpts from the United States Renal Data System (USRDS) (2001) 2001 Annual data report: atlas of end-stage renal disease in the United States. Am J Kidney Dis 38(S3):S1S176

Fradin S, Goulet-Salmon B, Chantepie M, Grandhomme F, Morello R, Jauzac P, Reznik Y (2002) Relationship between polymorphisms in the renin-angiotensin system and nephropathy in type 2 diabetic patients. Diabetes Metab 28:27-32

Freire MB, Ji L, Onuma T, Orban T, Warram JH, Krolewski AS (1998) Gender-specific association of M235T polymorphism in angiotensinogen gene and diabetic nephropathy in NIDDM. Hypertension 31:896-899

Grzeszczak W, Zychma MJ, Lacka B, Zukowska-Szczechowska E (1998) Angiotensin I-converting enzyme gene polymorphisms: relationship to nephropathy in patients with noninsulin dependent diabetes mellitus. J Am Soc Nephrol 9:1664-1669

Jacobsen P, Tarnow L, Carstensen B, Hovind P, Poirier O, Parving HH (2003) Genetic variation in the renin-angiotensin system and progression of diabetic nephropathy. J Am Soc Nephrol 14:2843-2850

Jaimes EA, Galceran JM, Raij L (1998) Angiotensin II induces superoxide anion production by mesangial cells. Kidney Int 54:775-784

Jeunemaitre X, Soubrier F, Kotelevtsev YV, Lifton RP, Williams CS, Charru A, Hunt SC, Hopkins PN, Williams RR, Lalouel JM (1992) Molecular basis of human hypertension: role of angiotensinogen. Cell 71:169-180

Kagami S, Border WA, Miller DE, Noble NA (1994) Angiotensin II stimulated extracellular matrix protein synthesis through induction of transforming growth factor- $\beta$ expression in rat glomerular cells. J Clin Invest 93:2431-2437

Kanazawa A, Tsukada S, Sekine A, Tsunoda T, Takahashi A, Kashiwagi A, Tanaka Y, Babazono T, Matsuda M, Kaku K, Iwamoto Y, Kawamori R, Kikkawa R, Nakamura Y, Maeda S (2004) Association of the gene encoding wingless-type mammary tumor virus integration-site family member $5 \mathrm{~B}$ $(W N T 5 B)$ with type 2 diabetes. Am J Hum Genet 75:832843

Kimura H, Gejyo F, Suzuki Y, Suzuki S, Miyazaki R, Arakawa M (1998) Polymorphisms of angiotensin converting enzyme and plasminogen activator inhibitor-1 genes in diabetes and macroangiopathy. Kidney Int 54:1659-1669

Leehey DJ, Singh AK, Alavi N, Singh R (2000) Role of angiotensin II in diabetic nephropathy. Kidney Int 58(S77):S93-S98

Lewis EJ, Hunsicker LG, Bain RP, Rohde RD (1993) The effect of angiotensin-converting-enzyme inhibition on diabetic nephropathy. The collaborative study group. $\mathrm{N}$ Engl J Med 329:1456-1462

Marre M, Jeunemaitre X, Gallois Y, Rodier M, Chatellier G, Sert C, Dusselier L, Kahal Z, Chaillous L, Halimi S, Muller A, Sackmann H, Bauduceau B, Bled F, Passa P, AlhencGelas F (1997) Contribution of genetic polymorphism in the renin-angiotensin system to the development of renal complications in insulin-dependent diabetes. J Clin Invest 99:1585-1595

Mizuiri S, Hemmi H, Kumanomidou H, Iwamoto M, Miyagi M, Sakai K, Aikawa A, Ohara T, Yamada K, Shimatake H, Hasegawa A (2001) Angiotensin-converting enzyme (ACE) $\mathrm{I} / \mathrm{D}$ genotype and renal ACE gene expression. Kidney Int 60: 1124-1130

Ng DP, Tai BC, Koh D, Tan KW, Chia KS (2005) Angiotensin-I converting enzyme insertion/deletion polymorphism and its association with diabetic nephropathy: a meta-analysis of studies reported between 1994 and 2004 and comprising 14,727 subjects. Diabetologia 48:1008-1016

Ohnishi Y, Tanaka T, Ozaki K, Yamada R, Suzuki H, Nakamura Y (2001) A high-throughput SNP typing system for genomewide association studies. J Hum Genet 46:471-477

Patient Registration Committee, Japanese Society for Dialysis Therapy (2002) The current state of chronic dialysis treatment in Japan. J Jpn Soc Dial Ther 35:1155-1184

Rigat B, Hubert C, Alhenc-Gelas F, Cambien F, Corvol P, Soubrier F (1990) An insertion/deletion polymorphism in the angiotensin I-converting enzyme gene accounting for 
half the variance of serum enzyme levels. J Clin Invest 86:1343-1346

Tomino Y, Makita Y, Shike T, Gohda T, Haneda M, Kikkawa R, Watanabe T, Baba T, Yoshida H (1999) Relationship between polymorphism in the angiotensinogen, angiotensin-converting enzyme or angiotensin II receptor and renal progression in Japanese NIDDM patients. Nephron 82:139144

Yamada R, Tanaka T, Unoki M, Nagai T, Sawada T, Ohnishi Y, Tsunoda T, Yukioka M, Maeda A, Suzuki K, Tateishi H,
Ochi T, Nakamura Y, Yamamoto K (2001) Association between a single-nucleotide polymorphism in the promoter of the human interleukin-3 gene and rheumatoid arthritis in Japanese patients, and maximum-likelihood estimation of combinatorial effect that two genetic loci have on susceptibility to the disease. Am J Hum Genet 68:674-685

Zychma MJ, Zukowska-Szczechowska E, Lacka BI, Grzeszczak W (2000) Angiotensinogen M235T and chymase gene CMA/ $\mathrm{B}$ polymorphisms are not associated with nephropathy in type II diabetes. Nephrol Dial Transplant 15:1965-1970 